\title{
Analysis of Spoken Discourse Pattern in Nepali ELT Classes
}

Basudev Dahal

Abstract

Among a multitude of study areas, discourse analysis has emerged as a fast-growing discipline because of growing interest of linguists in studying language in natural setting, as opposed to making analyses of artificially created sentences. A concentrated amount of work on discourse analysis in the past few decades has demonstrated that discourse in classrooms is highly organized and amenable to analysis. This paper is an attempt to make an analysis of such a naturally occurring classroom discourse based on Sinclair-Coulthard analysis model developed in 1975.This model has come as a significant contribution for those who are interested in the field of discourse analysis. The study suggests that there is use of a simple discourse pattern in Nepali higher secondary classes of English.

Key words: Discourse analysis, spoken discourse, discourse structure, exchange, move

\section{Introduction}

Emerging from many disciplines such as linguistics, semiotics, psychology, anthropology and sociology, discourse analysis is an attempt to study how language is used in various situations. It is chiefly concerned with the study of the relationship between language and context in which it is used.

The interest of language teachers in discourse analysis has been increasing at speed, as it attempts to study how real people use language in natural setting, as opposed to studying artificial sentences one chooses to describe. While designing teaching materials; while engaging learners in exercises and activities aimed at making them proficient users of their target language; or while evaluating a piece of commercially published material before using it, we must have a question in mind of how people use language.

The casual conversation is probably the most frequent spoken discourse type in people's every life. Some other types include interviews, service counters in shops and offices, seminars, monologues, classroom interactions, public speeches, and so on. As a language teacher, one needs to decide which forms of speech are crucial and useful to learners of language. A language teacher not only should decide on the structures of different types of speech, he or she should also have sound knowledge of what is authentic and natural language. The teacher needs to know how speech follows a regular pattern in a variety of situations; how rules of speaking operate; and how one form of speech differs from another. Discourse analysis of naturally occurring language, therefore, is essential to a language teacher.

\section{Analysis of spoken discourse}

Discourse is broadly classified into two types: Spoken and written. Spoken discourse is highly informal and complex in its structure. McCarthy (1991, p. 118) says, "Spoken language is a vast subject, and little is known in hard statistical terms of the distribution of different types of the speech in people's everyday lives." Cook (1989, p. 115) gives a similar opinion, "Spoken language, as has often been pointed out, happens in time, and must therefore be produced and processed 'on line'. There is no going back and changing or 
restructuring our words as there is on writing ; there is often no time to pause and think, and while we are talking or listening, we cannot stand back and view the discourse in spatial or diagrammatic terms as we did." Spoken language, therefore, is often unplanned, less socially structured and more reciprocal. Casual conversation, which occurs most frequently among different types of speeches, is relatively unplanned and unpredictable, and involves frequent turn-taking and the use of interjections.

Making a description of spoken language, therefore, is a difficult enterprise. Spoken language is so complex that it is hard to make an objective judgment of it, without using a previously set analysis scheme. It is indeed by no means certain that the kind of descriptive systems grammarians have used so successfully is an appropriate tool for handling the structure of spoken interaction. There are virtually no commonly agreed descriptive systems for the analysis of patterns in spoken discourse. Coulthard and Brazil (1981) view that one notable obstacle in the way of developing a description of interaction is that "speakers seem to have weaker intuitions about permissible sequences of interactive units than they do about permissible sequences of grammatical units. It may be that this only happens to be the case because relatively little work has been done on the structure of interaction" (p.82). Difficulty in the analysis is evident from the fact that it is still not clear what the largest structrcal unit is in spoken discourse. For example, Sinclair and Coulthard (1975) point out that lesson is in the highest rank of discourse while Burton (1981) puts interaction in the top rank, and yet, Coulthard and Brazil (1981) see transaction as the largest structural unit of discourse. Moreover, many structural analyses of spoken discourse have been published, but little attempt has been made to motivate different rival analyses of the same data, and to decide which analysis is the best.

\section{Principles of interaction}

It is widely accepted fact that interaction proceeds according to certain principles. Linguistics has traditionally been concerned with characterizing well-formed and ill-formed units in terms of grammatical structures within sentences.
However, it is also important to realize that grammatical correctness is not sufficient to make one's speech well-formed. We must also look beyond the grammatical rules operating within sentences. It is also important to assure that various formal and contextual links are used in the interaction. Speakers must be able to distinguish coherent from incoherent discourse. In the following interaction between two friends A and B for example, A's utterance is heard to be ill-formed by B.

\section{A: I want to have my shoe repaired. Do you know a good tailor's around here? \\ B: Who did you say?}

The concept of well-formedness, however, is difficult to apply in spoken discourse. Various writers have emphasized that a discourse becomes meaningful with the use of cohesive devices such as references, substation ellipsis, conjunction, collocation, etc (e.g. Martin, 1981; Cook, 1989; Nunan, 1993). These are the formal links. In addition to these, speakers need to have the knowledge of the context in which language is used. Richardson (1981) says that an ideal interaction is characterized by synchronization. The principle of synchronization requires that all speakers are equally involved from the moment of the conversation's commencement to the moment of its termination. However, in real situation we rarely find all participants equally involved. Similarly, the conversational maxims of Grice (1975) and Lakoff (1973) have been very influential. According to the co-operative principle put forward by Grice, a speaker is supposed to be true, brief, relevant and clear. Likewise, Lakoff suggests a speaker not to impose, give options and make the hearer feel comfortable.

\section{Sinclair-Coulthard model of discourse analysis}

The analysis of classroom interaction presented in Sinclair and Coulthard (1975) is perhaps the most significant contribution among the analyses of naturally occurring discourse. This model of analysis was developed at the University of Birmingham which focused on the structure of discourse in traditional English native speaker school classrooms. This is a simple and powerful 
model, although it may not be the only authentic one (McCarthy, 1991).

Sinclair and Coulthard found that teachers and pupils interact in a fixed pattern based on their specific roles. The following example illustrates the point.

Teacher: Can you tell me why you eat all that food?

Yes.

Pupil: To keep strong.

Teacher: To keep strong. Yes. To keep strong.

Why do you want to be strong?

(Sinclair and Coulthard: 1975, p. 21)

This extract is an example of an exchange of teacher-pupil interaction which operates in a fixed pattern. As this example demonstrates, a typical exchange consists of an initiation by the teacher, which is followed by a response from the pupil, and which in turn is followed by a feedback from the teacher again. Initiation, response and feedback are termed opening move, response move and followup move respectively. The sequence of opening, response and follow up is called exchange. Sinclair and Coulthard discuss two classes of move. They are boundary exchange and teaching exchange. The above sequence is an example of a teaching exchange. Teaching exchange has five types. They are teacher-elicit, teacher-inform, teacherdirect, pupil-elicit and pupil-inform exchanges. In a teacher-elicit exchange, the teacher gets a pupil to provide some kind of verbal response; in a teacher-inform exchange the teacher provides an explanation which may or may not be responded by the pupil; in a teacher-direct exchange, the teacher gets the pupil to do an activity. In a pupilelicit exchange, the pupil asks a question usually to the teacher, and the teacher, if asked, always provides a response. In pupil-inform exchange, the pupil provides an explanation which is usually responded by the teacher. The following example illustrates a boundary exchange.

Teacher: Now then...I've got some things here, too. Hands up. What's that, what is it?

Pupil: Saw.

Teacher: Saw.

(Sinclair and Coulthard: 1975, p. 33)
Before beginning the interaction, the teacher says, "Now then". In teacher-pupil exchanges, we find people using such expressions as 'right', 'well', 'O.K.', 'now', etc. Such expressions are termed framing moves. After the framing move in the above example, the teacher uses another expression before asking the question (I've got some things here, too.) the function of such an expression is to tell the class what is going to happen. It is called a focusing move. Framing and focusing moves together realize a higher discourse unit called a boundary exchange. Thus, opening, response and follow-up moves realize a teaching exchange whereas framing and focusing moves realize a boundary exchange.

According to Sinclair and Coulthard, classroom interaction takes place with the use of framing moves. Some teachers habitually use the same frame frequently. Two framing moves together with question and answer sequences between them make a higher unit called transaction. The highest unit of classroom discourse consists of one or more transactions called lesson. Provided that pupils are responsive and cooperative, lesson may be close to any plan a teacher makes for a particular pedagogical unit, period. Sinclair and Coulthard tried to analyze classroom discourse in terms of the four units discussed so far: move, exchange, transaction and lesson. However, they felt difficulty in analyzing the structure of move. Later, they realized that moves are structured in terms of smaller units called acts. Sinclair and Coulthard (1975, p. 23) say, "Acts and moves in discourse are very similar to morphemes and words in grammar. By definition, move is the smallest free unit although it has a structure in terms of acts". Acts serve communicative function in the structure of moves. For example, among the twenty-two acts listed by Sinclair and Coulthard, 'marker' ( $m$ ) is realized by closed classes of items such as well. 'O.K.', 'now', 'good', 'right', 'alright', and has the function of marking boundaries in the discourse; and 'starter' (s), which is resized by statement, question or command, has the function of providing information about or direct attention to or thought towards an area in order to make a correct response to the initiation more likely (Sinclair and Coulthard, 1975). 


\section{The study}

The aim of this study was to analyze the structure of classroom interaction in Nepali ELT classes and compare it to the structure pointed out by Sinclair and Coulthard. For this, two higher secondary schools of Morang and Sunsari districts were selected. Altogether ten Compulsory English classes by three teachers of grades XI and XII were observed and audio-taped. Later, the recorded classes/data were analyzed using SinclairCoulthard analysis model of classroom discourse. The classes/data were analyzed in terms of the five discourse units mentioned in Sinclair and Coulthard (1975): lesson, transaction, exchange, move and acts. Among these five units, exchange and move were mainly focused. The analyzed classes were found to be similar as well as deviant from the discourse structures suggested by Sinclair and Coulthard.

\section{Major findings and discussion}

The first question asked during the classroom observation was whether different language teachers would differ in their teaching. The teachers were found to be using different techniques which of course were found to affect the structure of the interaction. The major findings of the study are discussed in terms of the major discourse units mentioned in Sinclair and Coulthard (1975).

The structure of the lesson was different from one class to another, and from on teacher to another. However, it was found that each lesson began with an exchange of greeting which was always opened by students. Interestingly, each analyzed/data lesson was found to be consisting of not more than six transactions.

As pointed out by Sinclair and Coulthard, each transaction was found beginning with a framing move by the teacher. The preliminary exchange was always opened with greeting which always lacked follow-up move and even sometimes response move by the teacher. Except the exchange of greeting, most of the other exchanges were controlled by the teacher. Among the three main exchanges (informing, directing and eliciting), there was over use of informing exchanges. Directing exchanges were sometimes used, mainly to maintain discipline in the class. Informing and directing exchanges rarely involved the use of response and feedback moves. In addition to these exchanges, it was also found that there was rare use of pupil-elicit and pupil- inform exchanges, as exemplified below.

Pupil: Sir, what is the meaning of porter?

Teacher: Don't you know that he carries loads?

Pupil: Oh.

(Pupil-elicit exchange)

Pupil: Sir, I think cove is a kind of bay.

Teacher: Oh yes, yes. But how did you know?

(Pupil-inform exchange)

It was found that both kinds of exchanges were used in the classrooms. Boundary exchanges were used by teachers alone. Teaching exchanges were used even by pupils, although in some occasional cases. Between the two types of moves in boundary exchange, Sinclair and Coulthard (1975, p. 49) claim, "...the framing move frequently occurs on its own, the focusing move does so only rarely." Contrary to this, however, many boundary exchanges were found which involved no use of frame. Framing moves were always found in the termination of a transaction, but they were frequently found absent in the initiation. Teachers were frequently found to be using fixed expressions for framing move habitually. Expressions like 'O.K', 'right', 'alright' were not only used in the framing moves but in the middle of teaching exchanges as mentioned in the following example.

Teacher: O.K.

First of all I will explain the title of this poem, O.K. Do you know th e meaning of 'grandeur'? ... No? ... Alright. Do you know?

Pupil: No, sir.

As described by Sinclair and Coulthard, framing moves were found to be followed by focusing moves optionally. In the structure of focusing move, I found the existence of optional pre-head followed by a compulsory head, but there was no use of post-head, which is used optionally by teachers, as Sinclair and Coulthard point out. An example is given below. 
Teacher: After this, [pre-head]

Let's discuss the questions given in your book. [head]

Among the three types of moves in the teaching exchange, opening move was always found to be used. Answering and follow up moves were never found to be used in the teacher-direct and teacherinform exchanges, but they were frequently found in teacher-elicit, pupil-elicit and pupil-inform exchanges. In the structure of teacher opening move, there was no use of 'signal', but other elements were found optionally except 'head', which of course, was always used. In the structure of pupil opening move, no use of 'signal', 'pre-head' and 'post head' was found, but select was found to be used frequently with 'head'. In the structure of pupil-answering move, only 'head' was found, but in teacher-answering move 'pre-head' and 'posthead' were also sometimes used. In teacher followup move, there was frequent use of 'pre-head' and 'post-head' in addition to the obligatory element, 'head'. However, pupil follow-up move involved the use of 'head' only. All the classes of act were found in the various classes of move. Among them 'marker' and 'acknowledge' were chiefly found to be used, particularly in teacher exchanges. Other classes of acts like 'elicitation', 'directive', 'silent stress' 'informative', accept', 'reply', bid', 'react' 'acknowledge' were also amply used. 'Meta-statement' and 'conclusion' were used occasionally. 'Evaluate' act was rarely used in student-response move.

During the study it was found that teachers were too prescriptive in terms of what constitutes appropriate behavior in the classroom. Consequently, learners' motivation was affected and they were found reluctant to participate in exchanges. They simply provided very short responses to teacher's opening moves without making the opening of exchanges themselves.

\section{Conclusion}

This study reveals a simpler structure of classroom discourse than the one mentioned by Sinclair and Coulthard. Particularly there was absence of 'pre-heads' and 'post-heads' in moves of various types. Among the five types of teaching exchanges, teacher-inform move was found to be used chiefly. This may be because of the fact that Sinclair and
Coulthard describe native speaker classroom discourse which does not have the same pattern as that of a non-native language classroom, where learners depend largely on one- directional chalkand-talk teacher-inform exchanges.

The findings of the present study have practical educational implications in second language learning and teaching. On the one hand, second language learners may need to understand pragmatic aspects of the target culture better in order not only to speak grammatically but also to interpret appropriately what they hear, and to interact effectively with members of the target culture. On the other hand, second language teachers may need to incorporate many crosscultural discourse analyses in their teaching in order to address learners' possible communicative problems. In this way, second language teachers can better help learners avoid lapsing unconsciously into the norms of their native language and thus causing unintended offense. This study is still insightful, for it gives some information about what teachers do with language when they speak and how they speak the language. With the analyses of this, we are able to know the relationship between language and particular contexts and users. Making the comparisons of discourse pattern in our contexts with that of native speaker classroom helps teachers to make up their minds as to whether their methods and techniques need rethinking in light of what discourse analysts suggest.

Basudev Dahal teaches at Sukuna Multiple Campus, Morang and Vishwa Adarsha College, Itahari, Sunsari.His areas af interest include Pragmatics and Discourse Analysis. He has five years experience of teaching English Phonoogy, Semantics, Pragmatics and Discourse Analysis. He is aso a life member of NELTA, and is particulraly interested in teaching young learners.

\section{References}

Burton, D. (1981). Analysing spoken discourse. In Coulthard, M. \& Montgomery (Eds.), Studies in discourse analysis (pp. 61-81). London: Routledge \& Kegan Paul Ltd.

Cameron, D. (2007). Working with spoken discourse. London: Sage Publication.

Cook, G. (1989). Discourse. Oxford: Oxford University Press. 
Coulthard, M \& Brazil, D. (1981). Exchange structure. In Coulthard, M. \& Montgomery (Eds.), Studies in discourse analysis (pp. 82-106). London: Routledge \& Kegan Paul Ltd.

McCarthy, M. (1991). Discourse analysis for language teachers. Cambridge: Cambridge University Press.

Richardson, K. (1981). Sentences in discourse. In Coulthard, M. \& Montgomery (Eds.), Studies in discourse analysis (pp. 51-60), London: Routledge \& Kegan Paul Ltd.

Sinclair, J \& Coulthard, R.M. (1975) Towards an analysis of discourse.Oxford: Oxford University Press.

Wood, L.A. \& Kroger, R. O. (2003). Doing discourse analysis. London: Sage publication. 